\title{
Identification of Limited English Proficient Patients in Clinical Care
}

\author{
Leah S. Karliner, MD MCR ${ }^{7}$, Anna M. Napoles-Springer, $P h D M P H^{7}$, Dean Schillinger, $M D^{2}$, \\ Kirsten Bibbins-Domingo, MD PhD², and Eliseo J. Pérez-Stable, $M D^{7}$
}

'Division of General Internal Medicine and Medical Effectiveness Research Center for Diverse Populations, Department of Medicine, University of California San Francisco (UCSF), San Francisco, CA, USA; ${ }^{2}$ Division of General Internal Medicine, Department of Medicine, Center for Vulnerable Populations, San Francisco General Hospital, UCSF, San Francisco, CA, USA.

BACKGROUND: Standardized means to identify patients likely to benefit from language assistance are needed.

OBJECTIVE: To evaluate the accuracy of the U.S. Census English proficiency question (Census-LEP) in predicting patients' ability to communicate effectively in English.

DESIGN: We investigated the sensitivity and specificity of the Census-LEP alone or in combination with a question on preferred language for medical care for predicting patient-reported ability to discuss symptoms and understand physician recommendations in English.

PARTICIPANTS: Three hundred and two patients > 18 who spoke Spanish and/or English recruited from a cardiology clinic and an inpatient general medicalsurgical ward in 2004-2005.

RESULTS: One hundred ninety-eight (66\%) participants reported speaking English less than "very well" and 166 (55\%) less than "well"; 157 (52\%) preferred receiving their medical care in Spanish. Overall, 135 $(45 \%)$ were able to discuss symptoms and $143(48 \%)$ to understand physician recommendations in English. The Census-LEP with a high-threshold (less than "very well") had the highest sensitivity for predicting effective communication (100\% Discuss; 98.7\% Understand), but the lowest specificity (72.6\% Discuss; $67.1 \%$ Understand). The composite measure of Census-LEP and preferred language for medical care provided a significant increase in specificity (91.9\% Discuss; $83.9 \%$ Understand), with only a marginal decrease in sensitivity (99.4\% Discuss; 96.7\% Understand).

CONCLUSIONS: Using the Census-LEP item with a high-threshold of less than "very well" as a screening question, followed by a language preference for medical care question, is recommended for inclusive and accurate identification of patients likely to benefit from language assistance. (246 words)

KEY WORDS: limited English proficiency; LEP; language barriers; clinical care; effective communication.

Received October 9, 2007

Revised April 3, 2008

Accepted May 22, 2008

Published online July 10, 2008
$\mathrm{J}$ Gen Intern Med 23(10): 1555-60

DOI: $10.1007 / \mathrm{s} 11606-008-0693-y$

(c) Society of General Internal Medicine 2008

\section{INTRODUCTION}

In 2000, 47 million U.S. residents spoke a language other than English at home. ${ }^{1,2}$ More than 19 million of them spoke English less than very well and were considered by the U.S. Census to have limited English proficiency (LEP). ${ }^{2}$ Increasingly, policy makers are recognizing the importance of language barriers as a contributor to health care disparities. ${ }^{3-5}$ Communication across language barriers is fundamental to the provision of safe and effective health care for diverse populations. ${ }^{6,7}$

Language factors may contribute to health disparities at many points in the continuum of care. Patients with language barriers have less access to a usual source of care, and lower

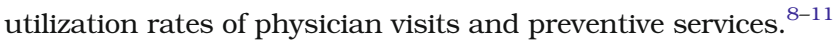
Although this association may be confounded by insurance status, it is evident that LEP patients experience disparities even when they do have access to care: LEP patients are less likely to comprehend their diagnosis and treatment, less likely to adhere with treatments and follow-up, more likely to experience medical errors in the hospital, and report less satisfaction with their care than English proficient patients. ${ }^{12-16}$ Use of professional interpreters in clinical settings or language concordant clinicians may decrease these language-related disparities in the quality and outcomes of care. ${ }^{15,17,18}$

A prerequisite for health care organizations and clinicians to address these disparities is to identify those patients most likely to benefit from language assistance. According to the Department of Justice guidance on implementing the Civil Rights Act (Title VI) for LEP persons, language assistance can take many forms, including language concordant clinicians and staff, and professional interpreter services provided either in person or remotely via telephone or videoconferencing. ${ }^{19-21}$ To encourage health care organizations to track language associated disparities and address these, the Joint Commission on the Accreditation of Healthcare Organizations (JCAHO) now requires the maintenance of records on patients' "language and communication needs." ${ }^{4}$ In a recent review of 60 representative U.S. hospitals, JCAHO found that systems for collection of required data on language and communication needs were "underdeveloped" and used inconsistently. ${ }^{22}$ Thus, there remains a clear need for a standardized and practical method that can be used by health care organizations and 
clinicians to identify routinely those patients who would most benefit from language assistance.

Remarkably, there is a lack of evidence-based methods for identifying LEP patients who would benefit from language assistance in health care settings. One simple option for identifying LEP patients is to use the U.S. Census question on English language proficiency. An advantage of this method is that it facilitates comparisons on the population distribution of LEP patients across settings and regions. ${ }^{1}$ However, the sensitivity and specificity of this question for identifying those patients who truly need language assistance services in a clinical setting has not been studied. Furthermore, the relationship of the U.S. Census item to effective communication in English in a clinical setting is unknown. Typically, hospitals tend to ask patients about the need for an interpreter during the medical visit or about language preference for medical care, but these questions have also not been studied. Furthermore, patients may underestimate their "need" for interpretation or may intentionally avoid being classified as needing English language assistance because they fear delays in care, being categorized as LEP, and language-based discrimination.

We sought to determine if the U.S. Census English proficiency question (Census-LEP) identifies adequately those patients who experience problems communicating effectively in English with their physicians. When used as a single item indicator, we examined how well two response thresholds for this item performed in identifying patients who reported ineffective communication with their physicians in English. Furthermore, we examined the performance of the CensusLEP item when used in combination with a question about preferred language for receipt of medical care.

\section{METHODS}

\section{Design, Setting and Participants}

The study was a cross-sectional analysis of baseline survey responses of participants from two sites in a study of language barriers and communication. We recruited patients from the Alameda County Medical Center cardiology clinic and inpatient general medical-surgical ward with the goal of obtaining a Spanish-speaking Latino sample and an English-speaking comparison group of any ethnicity. Recruitment occurred between March 2004 and August 2005. Bilingual research assistants identified Spanish-speaking patients by surname and primary language as it was listed on the clinic schedule or on the inpatient board and registration card, and by consulting nursing staff at both locations. Research assistants then confirmed the patient's primary language at the time of enrollment. On the days that interviewers were on site, efforts were made to recruit all patients who appeared to be primarily Spanish speakers; the days of the week on which recruitment occurred were varied to include a representative sample of LEP patients. For purposes of comparison, English speakers were recruited at both sites over the same time period as the Spanish speakers.

Informed consent was obtained from patients prior to their baseline interview. Individuals were excluded if they were younger than 18 years old, spoke a language other than English or Spanish, or failed a cognitive screen at the beginning of the interview (Mini-Cog). ${ }^{23-26}$ Research assistants conducted a face-to-face interview with the participants in their language of choice. The institutional review boards of the University of California San Francisco and Alameda County Medical Center approved the protocol.

\section{Outcomes and Follow-up}

Demographic variables included age, gender, and self-reported ethnicity. Three language-related variables were used in this analysis: English proficiency, language preference for medical care, and potential benefit derived from language assistance services. First, to assess English proficiency, participants were asked the Census-LEP item: "How well do you speak English?" Response options were "not at all, not well, well, or very well". Second, to assess language preference, participants were asked, "In general, in what language do you prefer to receive your medical care?” Response options were "English, Spanish, or both equally". The language preference item was dichotomized into English and English and Spanish equally, versus Spanish. Finally, we created the composite variable "benefit from language assistance" by combining the Census-LEP with the language preference for medical care question as described in the Figure. This new composite variable "benefit from language assistance" was dichotomous, with individuals categorized as likely to benefit (benefit group) versus unlikely to benefit (no benefit group) from language assistance. Persons answering "not at all" or "not well" to the Census-LEP were included in the "benefit" group; in addition, those answering "well" but indicating their language preference as Spanish, were also categorized in the "benefit" group. Those patients either answering "very well", or answering "well" to the CensusLEP but reporting their language preference as English or both English and Spanish equally, were categorized as "no benefit."

We assessed participants' self-reported ability to communicate effectively in English with their physicians (outcome variables) using the questions: "How well can you discuss your symptoms with your doctors in English?" and, "How well can you understand your doctors' recommendations in English?" These questions were asked immediately preceding the visit for the cardiology clinic patients, and during hospitalization for the inpatients. Both communication questions had the same response options as the Census-LEP question. As used in prior research on physician communication, ${ }^{27}$ each of these questions was dichotomized, such that only those answering "well" or "very well" were considered able to communicate effectively in English with their physicians.

\section{Statistical Analysis}

Statistical analyses were performed using STATA $9 .^{28}$ We used receiver operating curves (ROC) ${ }^{29-31}$ to assess the value of two different response thresholds of Census-LEP-a high threshold of less than "very well" (LEP) vs. "very well" (Englishproficient), and a mid-threshold of less than "well" (LEP) vs. greater than or equal to "well" (English-proficient)—in predicting effective communication with physicians. Thus, the high threshold definition of LEP included those who responded "well" to the U.S. Census question, and the mid-threshold did not. Using the two outcomes of patient-reported ability to discuss symptoms and to understand physician recommendations in English as the gold standard, we compared the 
sensitivity and specificity of the following: 1) each of these two response thresholds of the Census-LEP question alone; 2) the preferred language for medical care question alone; and 3) the new composite variable "benefit from language assistance".

\section{RESULTS}

Of 423 patients approached, 302 (72\%) participated and 121 declined-152 were recruited from the cardiology clinic and 150 from the inpatient ward. Fifty-eight percent (176) were interviewed in Spanish. More than half (66\%) reported speaking English less than "very well," and 55\%, less than "well." Fifty-two percent (157) preferred to receive their medical care in Spanish only, and based on the algorithm in Figure 1, 57\% (171) were classified as likely to benefit from language assistance (Table 1). The mean age of the participants was 46 years (range 18-84). The majority of participants selfidentified as Latino and African American. All of the white, African American and Asian participants were interviewed in English; $12 \%$ of the Latino participants were interviewed in English.

Overall, 135 (46\%) reported that they were able to discuss their symptoms effectively and $143(48 \%)$ reported that they were able to understand physician recommendations effectively in English. Of those interviewed in Spanish, 19 (11\%) reported being able to discuss their symptoms and 29 (16\%) to understand their physicians' recommendations "well" or "very well" in English.

Four participants who reported a preference for receipt of medical care in English, and 10 participants who reported equal preference for English and Spanish, also reported that they spoke English "not at all" or "not well" (Table 2). Only seven participants who spoke English less than "well" reported that they could discuss their symptoms effectively with their

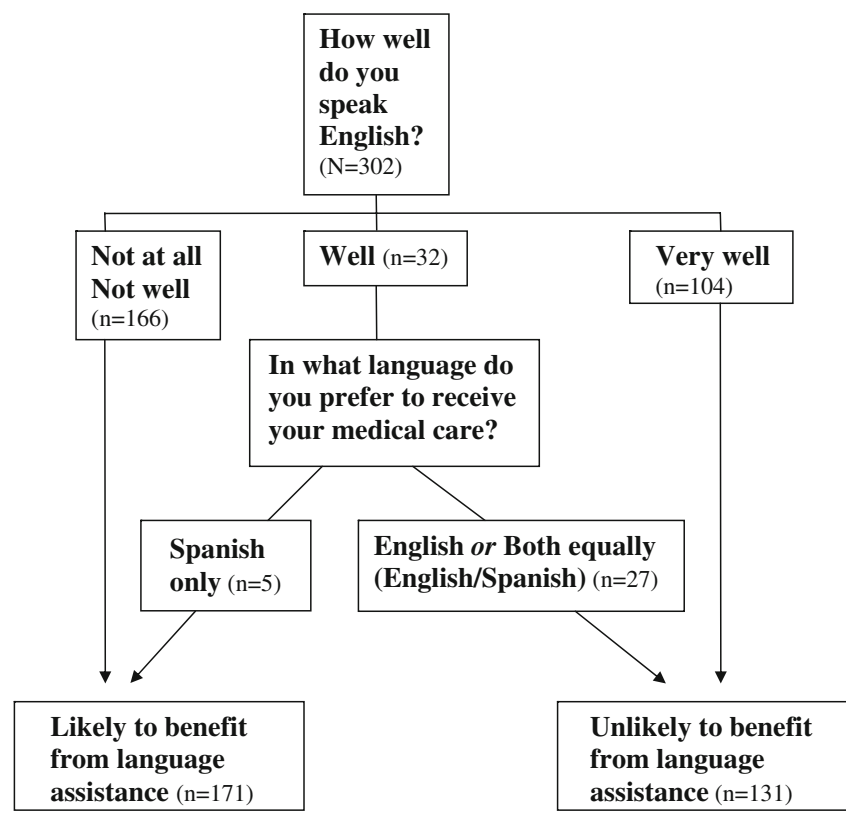

Figure 1. Algorithm for determining likely benefit from language assistance.
Table 1. Language Preferences and Proficiency Among Patients Seen at a County Hospital Medical Center, 2004-2005

\begin{tabular}{ll}
\hline \hline & N (\%) \\
\hline Ethnicity & \\
African American & $62(21)$ \\
Asian & $12(4)$ \\
Latino & $198(66)$ \\
White & $18(6)$ \\
Other/Mixed ethnicity & $12(4)$ \\
Age (mean years \pm s.d.) & $46 \pm 16$ \\
Women & $171(57)$ \\
Spanish language of interview & $176(58)$ \\
U.S. Census question (“How well do you speak English?") & \\
Not at all & $89(29)$ \\
Not well & $77(26)$ \\
Well & $32(11)$ \\
Very well & $104(34)$ \\
Preferred language for receipt of medical care & \\
English & $125(41)$ \\
Spanish only & $157(52)$ \\
Both equally & $20(7)$ \\
Likely to benefit from language assistance & $171(57)$ \\
Able to discuss symptoms in English & \\
Not at all & $93(31)$ \\
Not well & $68(23)$ \\
Well & $52(18)$ \\
Very well & $83(28)$ \\
Able to understand physicians' recommendations & \\
English & \\
Not at all & \\
Not well & $88(30)$ \\
Well & $65(22)$ \\
Very well & $59(20)$ \\
\hline
\end{tabular}

$*(N=302)$

*Percentages may not add up to 100 due to rounding error

doctors in English, while 19 reported that they could understand their doctors' recommendations effectively in English. The Spearman correlation coefficient for the Census-LEP (four responses) and the non-dichotomized effective communication outcome variables were 0.92 (discuss) and 0.88 (understand). There were no differences in effective communication by gender.

Table 3 summarizes the sensitivity and specificity of each of the four questions in predicting the outcomes of patient-

Table 2. U.S. Census English Proficiency Question Compared with Other Items Which Assess Language and Communication Needs in Clinical Settings Among Patients Seen at a County Hospital Medical Center, 2004-2005

\begin{tabular}{|c|c|c|c|c|}
\hline & \multicolumn{4}{|c|}{ "How well do you speak English?" } \\
\hline & $\begin{array}{l}\text { Not at all } \\
(n=89) \\
N(\%)\end{array}$ & $\begin{array}{l}\text { Not well } \\
(n=77) \\
N(\%)\end{array}$ & $\begin{array}{l}\text { Well } \\
(n=32) \\
N(\%)\end{array}$ & $\begin{array}{l}\text { Very well } \\
(n=104) \\
N(\%)\end{array}$ \\
\hline \multicolumn{5}{|c|}{ Preferred language for receipt of medical care } \\
\hline English & $1(1)$ & $3(4)$ & $17(53)$ & $104(100)$ \\
\hline Spanish only & $87(98)$ & $65(84)$ & $5(16)$ & $0(0)$ \\
\hline Both equally & $1(1)$ & $9(12)$ & $10(31)$ & $0(0)$ \\
\hline $\begin{array}{l}\text { Likely to benefit } \\
\text { from language } \\
\text { assistance }\end{array}$ & $89(100)$ & $77(100)$ & $5(16)$ & $0(0)$ \\
\hline \multicolumn{5}{|c|}{ Able to discuss symptoms in English } \\
\hline Well/Very well & $0(0)$ & $7(9)$ & $30(94)$ & $98(100)$ \\
\hline \multicolumn{5}{|c|}{ Able to understand doctors' recommendations in English } \\
\hline Well/Very well & $2(2)$ & $17(22)$ & $28(88)$ & $96(98)$ \\
\hline
\end{tabular}


reported ability to discuss symptoms and to understand physician recommendations in English. Of all the indicators evaluated, the Census-LEP item using the high-threshold of less than "very well" was the most sensitive (100\% Discuss; 98.7\% Understand)—and thus the most inclusive-for predicting both of the effective communication outcomes; however, it was also the least specific for both outcomes (72.6\% Discuss; $67.1 \%$ Understand). The composite variable of benefit from language assistance afforded a significant increase in specificity (91.9\% Discuss; 83.9\% Understand), with only a marginal decrease in sensitivity (99.4\% Discuss; 96.7\% Understand) compared to the Census-LEP indicator with the high-threshold. The Census-LEP item using the mid-threshold of less than "well" was the most specific of the indicators for both effective communication outcomes $194.8 \%$ Discuss; $86.7 \%$ Understand), but it was also less sensitive (98.8\% Discuss; $96.1 \%$

Table 3. Comparison of Two Response Thresholds for the CensusLEP Question, Preferred Language for Medical Care, and Composite Variable "Benefit from Language Assistance" to Predict Effective Communication in English

\begin{tabular}{llll}
\hline \hline ROC & Sensitivity & Specificity \\
area & & \\
$(95 \% \mathrm{Cl})$ & & \\
\hline
\end{tabular}

\begin{tabular}{|c|c|c|c|c|}
\hline \multicolumn{5}{|l|}{$\begin{array}{l}\text { Census-LEP with } \\
\text { threshold of less } \\
\text { than "very well" }\end{array}$} \\
\hline $\begin{array}{l}\text { Discuss symptoms } \\
\text { in English well } \\
\text { or very well }\end{array}$ & $\begin{array}{l}0.86 \\
0.90)\end{array}$ & $10.82-$ & $100.0 \%$ & $72.6 \%$ \\
\hline $\begin{array}{l}\text { Understand } \\
\text { recommendations in } \\
\text { English well/very well }\end{array}$ & $\begin{array}{l}0.83 \\
0.87)\end{array}$ & $10 / 78-$ & $98.7 \%$ & $67.1 \%$ \\
\hline \multicolumn{5}{|l|}{$\begin{array}{l}\text { Census-LEP with } \\
\text { threshold of less } \\
\text { than "well" }\end{array}$} \\
\hline $\begin{array}{l}\text { Discuss symptoms in } \\
\text { English well/very well }\end{array}$ & $\begin{array}{l}0.97 \\
0.98)\end{array}$ & $10.94-$ & $98.8 \%$ & $94.8 \%$ \\
\hline $\begin{array}{l}\text { Understand } \\
\text { recommendations } \\
\text { in English } \\
\text { well/very well }\end{array}$ & $\begin{array}{l}0.91 \\
0.95)\end{array}$ & $10.88-$ & $96.1 \%$ & $86.7 \%$ \\
\hline \multicolumn{5}{|l|}{$\begin{array}{l}\text { Preferred language } \\
\text { for medical care }\end{array}$} \\
\hline $\begin{array}{l}\text { Discuss symptoms in } \\
\text { English well or } \\
\text { very well }\end{array}$ & $\begin{array}{l}0.91 \\
0.94)\end{array}$ & $10.87-$ & $96.9 \%$ & $84.4 \%$ \\
\hline $\begin{array}{l}\text { Understand } \\
\text { recommendations } \\
\text { in English } \\
\text { well/very well }\end{array}$ & $\begin{array}{l}0.87 \\
0.91)\end{array}$ & $10.82-$ & $95.4 \%$ & $78.3 \%$ \\
\hline \multicolumn{5}{|l|}{$\begin{array}{l}\text { Composite variable } \\
\text { of "Likely to benefit } \\
\text { from language } \\
\text { assistance" }\end{array}$} \\
\hline $\begin{array}{l}\text { Discuss symptoms in } \\
\text { English well or } \\
\text { very well }\end{array}$ & $\begin{array}{l}0.96 \\
0.98)\end{array}$ & (0.93- & $99.4 \%$ & $91.9 \%$ \\
\hline $\begin{array}{l}\text { Understand } \\
\text { recommendations } \\
\text { in English } \\
\text { well/very well }\end{array}$ & $\begin{array}{l}0.90 \\
0.93)\end{array}$ & $10.86-$ & $96.7 \%$ & $83.9 \%$ \\
\hline
\end{tabular}

Understand)-and thus less inclusive-than either the Census-LEP with the high-threshold or the benefit from language assistance indicator. The question on preferred language for medical care alone was the least sensitive and specific for predicting both outcomes.

\section{DISCUSSION}

Our study found that the English proficiency question used in the U.S. Census is able to identify most patients who cannot communicate effectively with their physicians in English. While the cutoff used in the U.S. Census to define LEP as anyone who reports speaking English less than "very well" was the most sensitive measure for identifying all of the patients who reported they were unable to communicate effectively with their physicians, it was also the least specific. This lower specificity could lead to misclassification of some patients as LEP who are, in fact, able to effectively communicate in English with their physicians. This type of misclassification might lead to costly language assistance resources being deployed unnecessarily. On the other hand, the higher specificity along with the lower sensitivity afforded by use of the mid-threshold of speaking English less than "well" on the Census-LEP question may result in misclassifying LEP patients as English speakers and not offering them language assistance, which in turn might lead to poor communication or medical errors.

Our composite variable of likelihood of benefit from language assistance was derived from the Census English proficiency question and a language preference for medical care item. This composite variable maintained very high sensitivity, while significantly improving specificity compared to the less than "very well" threshold for the Census-LEP item alone. This suggests that adding a second question on language preference for medical care after screening with the U.S. Census question, can both inclusively identify patients who might benefit from language assistance, while maximizing the appropriate use of limited language resources. In practice, use of both items allows health care organizations and clinicians to err on the side of caution and patient safety while maintaining efficiency of service delivery. Thus, our findings support the use of both items in clinical settings to accurately identify patients who are most likely to benefit from language assistance, and to screen out those who are unlikely to benefit.

Our findings further demonstrate the importance of addressing language needs for the provision of high quality, patientcentered healthcare. In our study, it was apparent that selfreported lack of English fluency, restricted patients' ability to communicate effectively with their physicians. Those who rated their skills in English as speaking less than "well" were substantially more likely to report problems discussing their symptoms or understanding their physicians' recommendations in English, two processes fundamental to receiving quality healthcare. Use of single item or composite measures such as those described in this study is consistent with quality of care indicators developed by the National Committee on Quality Assurance (NCQA), the Agency for Healthcare Quality and Research (AHRQ), and the Foundation for Accountability 
(FACCT), which emphasize the importance of language preferences in assessing the quality of health care among diverse populations. ${ }^{32}$ Furthermore, the Department of Health and Human Services' Office of Minority Health supports collection in clinical settings of data on English proficiency and need for an interpreter. ${ }^{33}$ Identification of those patients who would benefit from language assistance-whether in the form of fluent, language concordant physicians or in the form of professional interpreter services-is a necessary step to optimizing patient-centered care for LEP individuals.

Our study was limited by the small number of participants who reported speaking English "well", thereby limiting our capacity to test the composite variable "benefit from language assistance". A larger sample from more clinical sites would have allowed for greater precision in the performance of the questions. Nonetheless, our study stands out among studies of language barriers for including both inpatient and outpatient clinical sites. Both the language indicators and effective communication measures were based on self-report rather than objective measures of English proficiency and communication, making it possible that our study under- or overestimated participants' English language communication abilities in the medical setting. However, the high correlations between the Census question and each of our effective communication questions supports the validity of these measures as indicators of need for language assistance in clinical settings. The correlation of the Census measure is highest with the ability to discuss symptoms with physicians item. It is possible that the differences in responses to the two effective communication questions (discussing symptoms and understanding doctors' recommendations) indicate that some participants did not understand the meaning or intent of these questions. Alternatively, these differences could reflect that both the Census and the discuss symptoms items ask about spoken language, while the understanding doctors item asks about aural comprehension.

In conclusion, our findings support the use of simple, feasible, and standardized measures in clinical settings to identify LEP patients who should be offered language assistance, preferably in the form of either fluent language concordant clinicians and staff, or professional interpreters. Our data support use of the U.S. Census English proficiency item with a high-threshold of less than "very well" as a screening question, followed by a question about language preference for receipt of medical care for the subset of patients who report speaking English "well". We recommend that health care systems and clinicians adopt a standardized method for identification of LEP patients and propose that the algorithm used in this study may meet this standard. It is our hope that this algorithm, when applied in a systematic manner, can be used to monitor the impact of providing language assistance and improve the quality of care for all limited English proficient patients.

Acknowledgement: This study was supported by grant no. 20061003 from the California Endowment and by grant no. P30AG15272 of the Resource Centers for Minority Aging Research program funded by the National Institute on Aging, the National Institute of Nursing Research, and the National Center on Minority Health and Health Disparities, National Institutes of Health.

Conflict of Interest: None disclosed.

Corresponding Author: Eliseo J. Pérez-Stable, MD; Division of General Internal Medicine and Medical Effectiveness Research Center for Diverse Populations, Department of Medicine, University of California San Francisco (UCSF), 400 Parnassus Avenue, A-405, Box 0320, San Francisco, CA 94143-0320, USA (e-mail: eliseops@medicine.ucsf. edu).

\section{REFERENCES}

1. Shin H, Bruno R. Language Use and English-Speaking Ability; 2000. http://www.census.gov/prod/2003pubs/c2kbr-29.pdf. Accessed May 12,2008

2. U.S. Bureau of the Census. Ability to Speak English; 2000. Census 2000 summary File 3(SF3) - Sample Data http://www.census.gov/population/ www/socdemo/lang_use.html Accessed May 23, 2008.

3. Hasnain-Wynia R, Baker DW. Obtaining data on patient race, ethnicity, and primary language in health care organizations: current challenges and proposed solutions. Health Serv Res. 2006;41(4 Pt 1):1501-1518.

4. JCAHO. Joint commission 2006 Requirements Related to the Provision of Culturally and Linguistically Appropriate Health Care: Joint Commission on Accreditation of Healthcare Organizations; 2006.

5. Lurie N, Jung M, Lavizzo-Mourey R. Disparities and quality improvement: federal policy levers. Health Aff (Millwood). 2005;24(2):354-364, Mar-Apr

6. Hedges Greising C. Patients with Limited English Proficiency: Results from a National Survey: HRET.

7. Johnstone MJ, Kanitsaki O. Culture, language, and patient safety: Making the link. Int J Qual Health Care. 2006;18(5):383-388, Oct.

8. Fiscella K, Franks P, Doescher MP, Saver BG. Disparities in health care by race, ethnicity, and language among the insured: findings from a national sample. Med Care. 2002;40(1):52-59.

9. Fox SA, Stein JA. The effect of physician-patient communication on mammography utilization by different ethnic groups. Med Care. 1991;29 (11): 1065-1082.

10. Kirkman-Liff B, Mondragon D. Language of interview:relevance for research of Southwest Hispanics. Am J Pub Health. 1991;81(11):13991404.

11. Woloshin S, Schwartz LM, Katz SJ, Welch HG. Is language a barrier to the use of preventive services. J Gen Intern Med. 1997;12(8):472-477.

12. Carasquillo O, Orav EJ, Brennan TA, Burstin HR. Impact of language barriers on patient satisfaction in an emergency department. JGIM. 1999;14:82-87.

13. Crane JA. Patient comprehension of doctor-patient communication on discharge from the emergency department. J Emerg Med. 1997;15(1): 1-7.

14. Gandhi TK, Burstin HR, Cook EF, et al. Drug complications in outpatients. J Gen Intern Med. 2000;15:149-154.

15. Manson A. Language concordance as a determinant of patient compliance and emergency room use in patients with asthma. Med Care. 1988;26(12):1119-1128.

16. Schillinger D, Machtinger EL, Wang F, Palacios J, Rodriguez M, Bindman A. Language, literacy, and communication regarding medication in an anticoagulation clinic: a comparison of verbal vs. visual assessment. J Health Commun. 2006;11(7):651-664, Oct-Nov.

17. Karliner L, Jacobs E, Chen A, Mutha S. Do Professional Interpreters Improve Clinical Care for Patients with Limited English Proficiency? A Systematic Review of the Literature. HSR. 2007;42(2).

18. Perez-Stable EJ, Napoles-Springer A, Miramontes JM. The effects of ethnicity and language on medical outcomes of patients with hypertension or diabetes. Med Care. 1997;35(12):1212-1219.

19. Title VI, Prohibtion Against National Origin Discrimination Affecting Limited English Proficient Persons. In: Administration NAaR, ed. Vol 69: U.S. National Archives and Record Administration; 2007:1763-1768. 
20. Martinez E. Language Access in Health Care Statement of Principles: Explanatory Guide: National Health Law Program; October 2006.

21. Perkins J, Youdelman M, Wong D. Ensuring Linguistic Access in Health Care Settings: Legal Rights and Responsibilities, 2nd Edition. Los Angeles: National Health Law Program; 2003.

22. Wilson-Stronks A, Galvez E. Hospitals, Language, and Culture: A Snapshot of the Nation: The Joint Commission and The California Endowment; 2007.

23. Brodaty H, Low LF, Gibson L, Burns $\mathbf{K}$. What is the best dementia screening instrument for general practitioners to use. Am J Geriatr Psychiatry. 2006;14(5):391-400.

24. Borson S, Scanlan JM, Chen P, Ganguli M. The Mini-Cog as a screen for dementia: validation in a population-based sample. J Am Geriatr Soc. 2003;51(10): 1451-1454.

25. Lorentz WJ, Scanlan JM, Borson S. Brief screening tests for dementia. Can J Psychiatry. 2002;47(8):723-733.

26. Scanlan J, Borson S. The Mini-Cog: receiver operating characteristics with expert and naive raters. Int J Geriatr Psychiatry. 2001;16(2):216-222.
27. Fernandez A, Schillinger D, Grumbach K, et al. Physician language ability and cultural competence. An exploratory study of communication with Spanish-speaking patients. J Gen Intern Med. 2004;19(2):167-174.

28. STATACorp. STATA User's Guide, Version 9. College Station, TX: STATA Press; 2005.

29. Centor RM. Signal detectability: the use of ROC curves and their analyses. Med Decis Making. 1991;11(2):102-106.

30. Zweig MH, Campbell G. Receiver-operating characteristic (ROC) plots: a fundamental evaluation tool in clinical medicine. Clin Chem. 1993;39 (4):561-577

31. Begg CB. Advances in statistical methodology for diagnostic medicine in the 1980's. Stat Med. 1991;10(12):1887-1895.

32. Bethell C, Carter KDL, Latzke B, Gowen K. Measuring and Interpreting Health Care Quality Across Culturally Diverse Populations: A focus on consumer-reported indicators of health care quality. Portland: Foundation for Accountability; 2003.

33. DHHS. Health Care Language Services Implementation Guide. http:// www.thinkculturalhealth.org. Accessed May 7, 2008. 